\title{
Higher-Taxon and Cross-Taxon Surrogates for Odonate Biodiversity in Brazil
}

\author{
Dana Moiana Vianna \& Paulo De Marco Júnior²*
}

\author{
${ }^{1}$ Pós-graduação em Ecologia, Conservação e Manejo da Vida Silvestre, Instituto de Ciências Biológicas - ICB, \\ Universidade Federal de Minas Gerais - UFMG, Belo Horizonte, MG, Brasil \\ ${ }^{2}$ Laboratório de Ecologia Teórica e Síntese, Departamento de Biologia Geral, Instituto de Ciências Biológicas - ICB, \\ Universidade Federal de Goiás - UFG, Goiânia, GO, Brasil
}

\begin{abstract}
Odonate distributional patterns have recently become a focus of a global biodiversity evaluation, but it may present large gaps in biogeographical information, especially in tropical areas, which suggests the need of a surrogate approach for setting conservation priorities. Here we assemble available information of distribution of Brazilian odonate species and try to evaluate two different surrogate possibilities: i) a higher-taxon approach based on genera richness, and ii) a cross-taxa approach using the larger-sized Libellulidae species. The species richness distribution pattern shows a bias toward areas near research centers or with easy accessibility. Only $29 \%$ of the territory had any distributional information about odonates. A higher association of genera richness and species richness was observed and remained high even after controlling for differences in sampling effort. Libellulidae species richness was also a good surrogate, despite the low cover of available information of Brazilian territory. Our results support the use of higher-taxa over other approaches but highlight the importance of intensify sampling especially at the Cerrado, Caatinga and Amazonian biomes.
\end{abstract}

Key words: Odonate Distribution, Biodiversity Surrogates, Conservation, Species Richness Gradients, Wallacean Shortfall.

\section{Introduction}

Habitat loss is considered one of the most important threats to Neotropical biodiversity (Laurance 1999). Land cover conversion produced an extensive loss of Atlantic Forest ecosystem, leaving about $5 \%$ of its original coverage (GalindoLeal \& Câmara 2003), while conversion to agriculture is the main threat to the Brazilian Cerrado and Caatinga. Despite being in a better situation, the Amazonia system is now threatened by an increasing forest conversion to pasture and to soybean agriculture (Silva et al. 2005). In those areas, biodiversity is in direct competition with land use for economic purposes, and this is an unfair competition.

Considering this scenario, the need of protecting natural areas far outstrips the resources available for conservation. Conservation of terrestrial biodiversity at regional or global scales are mostly based on protecting natural areas, which result in a great cost both in land acquisition and management (Bruner et al. 2004). Therefore, it is necessary to prioritize site selection efforts that maximize the benefits to biodiversity, while minimizing the cost of protection.

*Send correspondence to: Paulo De Marco Júnior Departamento de Biologia Geral, Universidade Federal de Goiás - UFG, Campus II, CP 24241, CEP 74690-970,

Goiânia, GO, Brazil

e-mail: pdemarco@icb.ufg.br
In order to do that, one of the basic steps is to know how biodiversity is distributed in space (Diniz et al. 2010). Nevertheless, the shortage and biases in the information on the species distribution is usually known as the "Wallacean Shortfall" (Diniz et al. 2010) and is identified as the greatest obstacle to tropical biodiversity conservation.

Both the accelerate rate of habitat loss and the shortage of biodiversity distribution information force the use of surrogates of biodiversity in the process of priority setting for conservation choices in many tropical areas (Araujo et al. 2004). Those surrogates need to be easily estimated and have a well-known relation to the total biodiversity to guarantee the success of this approach. Usually the candidates for surrogates are environmental diversity (Faith 2003), higher-taxa (Balmford et al. 2000) or other groups - the cross-taxa approach (Pawar et al. 2007) - which have better biogeographical information or are more easily sampled. This general approach was tested both in tropical and temperate areas, showing a small coincidence of the species richness of birds, butterflies, moths, plants and small mammals (Prendergast et al. 1993). Theoretically, the appropriateness of the surrogate approach may be a function of the group under study, of the degree of strength with which environmental conditions have shaped past 
and present distribution of the groups and of the similarity between the processes that affect species richness in distant and similar taxa. Consequently, it is necessary to continue to evaluate this approach for different groups in order to produce practical conservation priorities.

The usage of genera or family richness as a surrogate for species richness is defended because these levels may be more sensitive to environmental variation and will be related to a large range of species. Usually, it is observed a high correlation between species diversity at higher levels and species richness (Balmford et al. 2000; Grelle 2002). Logically, an intrinsic relation between these variables is expected, but this approach only seeks to evaluate if it is sufficiently strong and homogeneous for several groups and sites to be useful. Some important advantages of this approach are the reduced cost and dependence on highly qualified taxonomists, usually required to identify species in megadiverse groups such as insects from tropical areas. In some cases, the identification at genera level takes $50 \%$ less time than to species level (Balmford et al. 2000). However, this strategy was tested mainly in groups with small species numbers, such as mammals and birds (Balmford et al. 2000).

Insects are largely used in studies of applied tropical biology, community diversity and habitat conservation. They are abundant, and can be studied by simple collecting methods, being usually a good choice for rapid assessment of biodiversity for environmental assessment purposes (McGeoch 1998). The Odonata order is considered an indicator of environmental alterations due to several of its general characteristics: i) they are flying terrestrial insects and highly diverse in neotropical areas (De Marco Junior \& Vianna 2005); ii) their adults depend on water bodies for reproduction and on the vegetation cover where they prey upon small animals, being affect both by aquatic and terrestrial habitat quality changes; iii) many adults are territorial and its presence may also indicate good environmental conditions for larval development (Silva et al. 2010). Oertli (2008) also emphasizes the facility to do quantitative studies and its ability to emulate sympathy and public awareness. Nevertheless, there is a large variation in the level of taxonomic and biogeographic distribution knowledge among the families of Odonata. As in other insects, some large and conspicuous groups are better known. In Odonata, the family Libellulidae seems to fit in this category, being intensely studied in respect of its natural history, taxonomy, phylogenetics and behaviour, partially due to how easily they can be found and sampled.

Considering the efforts for describing species richness distribution and the limits imposed by data shortage, we tested here two surrogate approaches to predict species richness in Odonata: i) the higher-taxa, and ii) species richness of the more common and easily identified Libellulidade group

\section{Methods}

\section{Basic distributional and environmental data}

All information on species distribution was assembled from an extensive literature review (see De Marco Junior \& Vianna 2005 for the complete list), and the information from some collections (Laboratório de Ecologia Teórica e Síntese, Universidade Federal de Goiás collection, F. Lencione collection). In many cases, the geographic position was determined from locality information present on the articles or collections. We standardized this information using the database of Brazilian cities of the Instituto Brasileiro de Geografia e Estatística (IBGE, www.ibge.gov.br, 10/ jun/2004), including digital maps at appropriate resolution to identify lakes, streams and farms.

\section{Data analysis}

All analysis was done using a grid map of Brazilian territory with 1 degree cell size as in other conservation biogeography studies (Pawar et al. 2007). The analysis and maps were prepared using DIVA/GIS (www.diva-gis.org/). We consider the basic sampling unit the record of a species in a site in a given collection day. This information is usually present on museum specimen labels and in articles of odonate systematics. Using this criterion, the sampling effort was estimated for each cell in the grid simply as the number of records.

To avoid the biases generated by uneven sampling effort among cells, we used the rarefaction method for species richness comparison. This method is basically the calculation of the estimated number of species in a given standardized sample (Sanders 1968) using the Equation 1.

$$
\mathrm{E}\left(\hat{\mathrm{S}}_{n}\right)=\sum_{\mathrm{i}=1}^{\mathrm{s}}\left[1-\frac{\left(\begin{array}{c}
N-N_{\mathrm{i}} \\
n
\end{array}\right.}{\left(\begin{array}{l}
N \\
n
\end{array}\right)}\right]
$$

where: $E\left(S_{N}\right)=$ expected number of species in an standardize sample of $\mathrm{n}$ records; $S=$ total species richness in the complete sample; $N_{I}=$ Number of records of the species $i ; N=$ total sampling effort $=\Sigma N_{i} ; n=$ chosen standardized sample $(n<N)$. We choose $n=50$ records as a balance between the decrease in the number of cells in the analysis (which resulted from using a large $n$ ) and the decrease in the discrimination power among cells (which resulted from using a small $n$ ).

An important confounding variable to understanding patterns of species richness variation is its intrinsic spatial autocorrelation, which may generate biased significance levels in statistical analysis (Bini et al. 2009). As our main interest here is evaluating the predictive power of genera and Libellulidae richness on the total odonate species 
richness, we used simple correlations measures with degree of freedom corrections for spatial autocorrelation according to Dutilleul (1993). A global Moran' I (Legendre \& Legendre 1998) was also estimated to check the magnitude of spatial autocorrelation of the dependent variable. All analysis were performed using SAM 4.0 ("Spatial Analysis for Macroecology”) software (Rangel et al. 2010).

\section{Results}

The area of Brazil encompasses 851 cells in our grid, out of which only 247 cells contain published odonate records. This means that the total 6203 records from Brazil are distributed only in $29 \%$ of the territory, which is a sound evidence of the need for biodiversity inventories (Figure 1). Both observed species richness (Figure 1a) and genera richness (Figure 1b) are concentrated in some regions from Rio de Janeiro, Minas Gerais and São Paulo states, at the Amazon river basin and some isolated points (e.g. Cuiabá municipality). The Moran's I spatial autocorrelation coefficient of species richness in this map was equal to $0.642(\mathrm{p}=0.05)$.
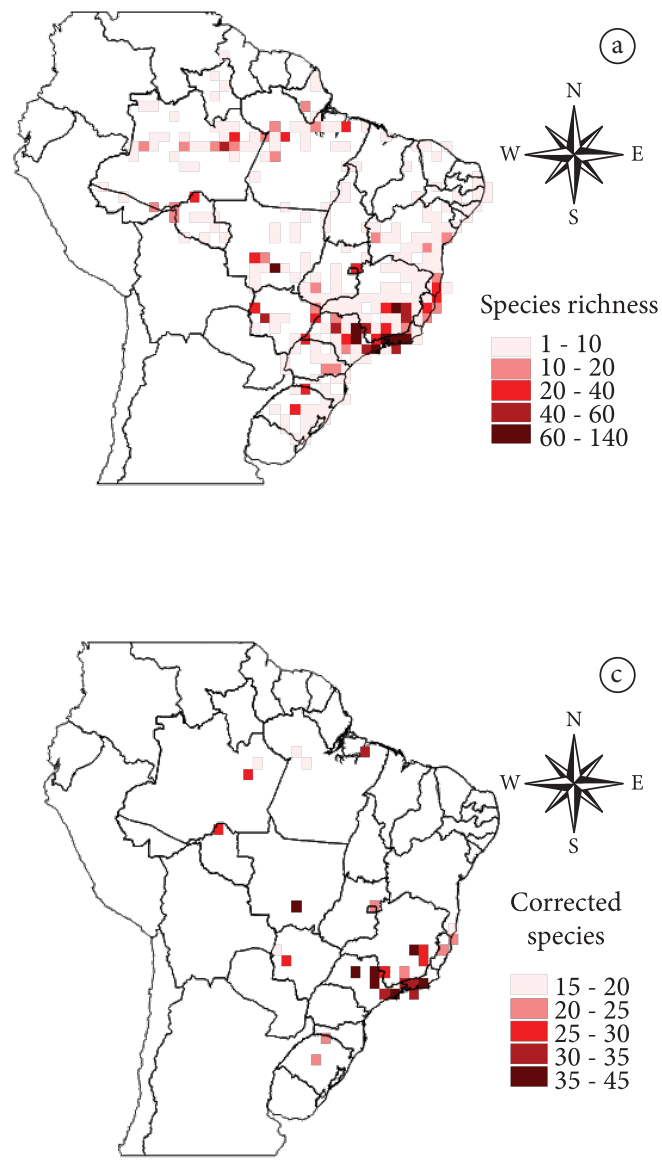

There is a clear sampling effort dependent distribution of species richness in Figure 1. Some small group of active odonate researchers, as Dr. Ângelo Machado, in Minas Gerais, Frederico Lencioni in São Paulo and Dr. Newton Santos, Dra. Janira Costa and Dr. Alcimar Carvalho, from Rio de Janeiro, seem to determine the distribution of odonate species in this map. Considering this bias, the first question is: which pattern will emerge if we control for sampling effort? Using the rarefaction technique to control this, some areas remain as rich sites including Rio de Janeiro (Rio de Janeiro), areas around Belo Horizonte (Minas Gerais) and Cuiabá (Mato Grosso) (Figure 1c). The general pattern is similar for the genera richness map (Figure 1d).

Based on observed biodiversity, species richness is highly correlated to genera richness $(R=0.978$, corrected $\mathrm{df}=96$, $P<0,001$; Figure 2a) and this relation remain high even after applying a rarefaction correction for sampling effort $(R=0.912$, corrected $\mathrm{df}=22, P<0,001$; Figure $2 \mathrm{~b})$.

There is a strong correlation between the more easily identified Libellulidae species richness and total Odonata richness $(R=0.933$, corrected $\mathrm{df}=12, P<0.001$; Figure $2 \mathrm{c})$.
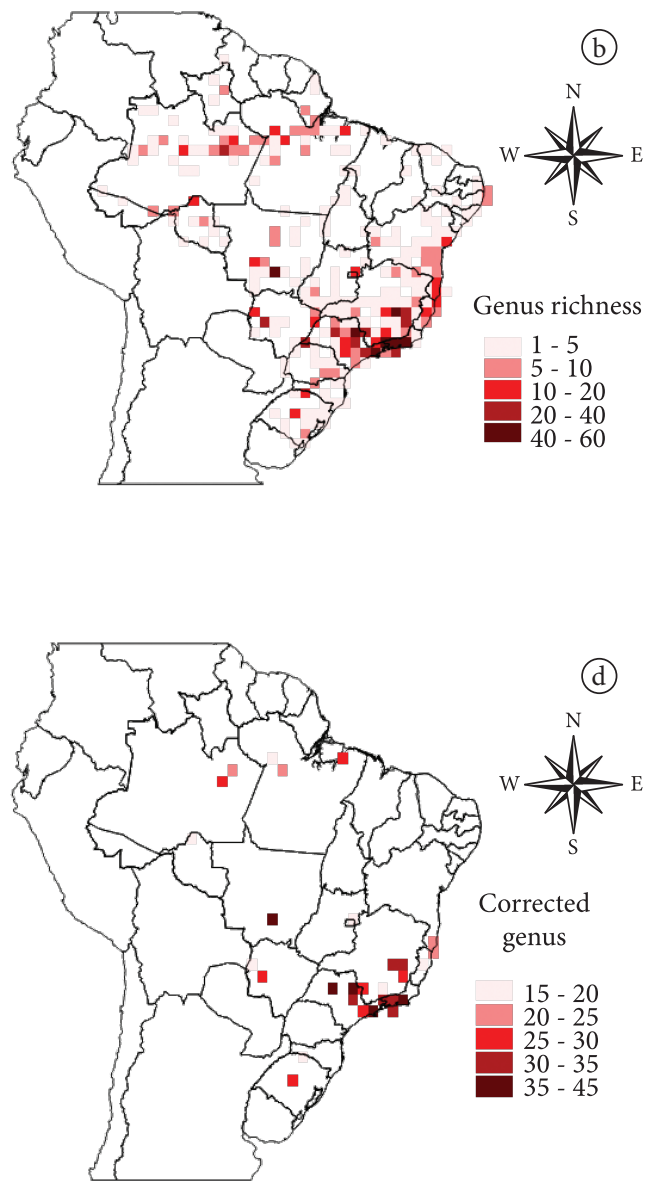

Figure 1. The distribution of observed species richness (a) and genera richness (b) and sampling-effort corrected estimation of species richness (c) and genera richness (d) of odonata in brazil in a one degree-cell grid. Sampling effort correction was based on rarefaction sampling of 50 records. 
(a)

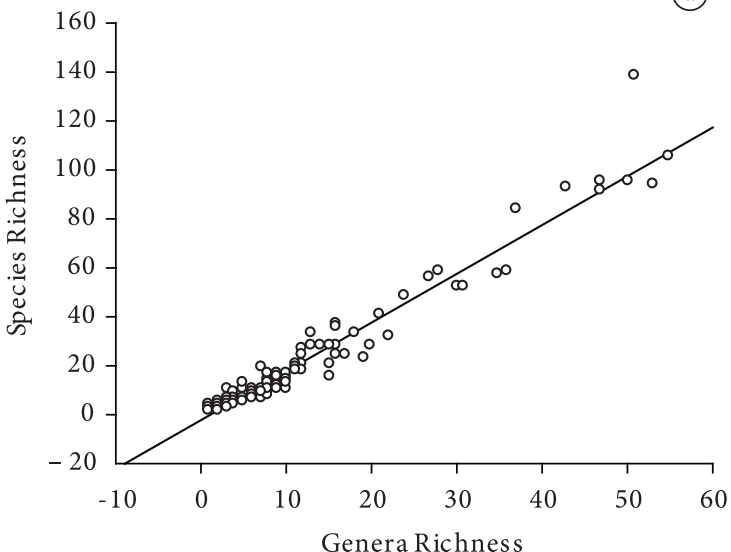

(c)

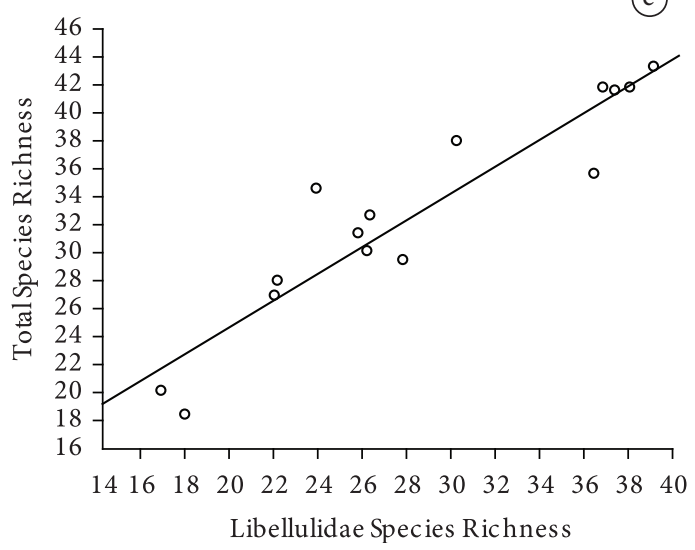

(b)

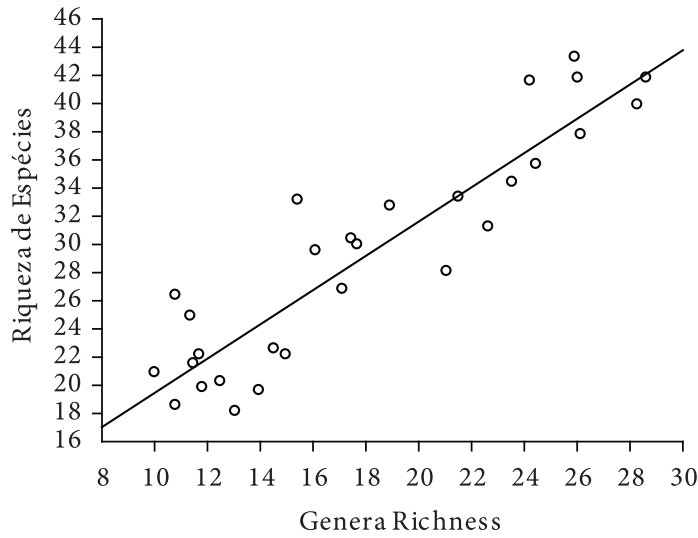

(d)

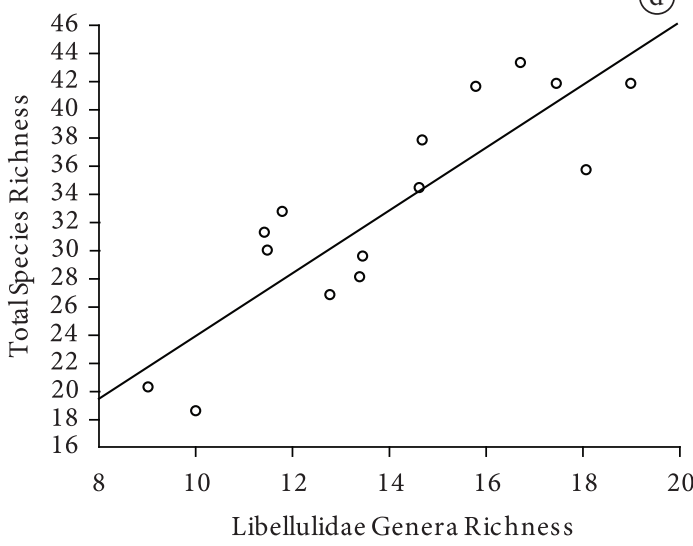

Figure 2. Linear regression for prediction of species richness from genera richness of Odonata in Brazil based on raw data (a) and sampling effort control by rarefaction method (b) and for Libellulidae species richness (c) and Libellulidae genera richness (d) both based on sampling effort controlled estimation of species richness based on a sample of 50 records using the rarefaction procedure.

This correlation decrease if we use Libellulidae genera richness as a prediction of total odonate richness, but it maintains a high predictive power $(R=0.856$, corrected $\mathrm{df}=12, P<0.001 ;$ Figure 2D).

\section{Discussion}

The spatial autocorrelation of the species richness could result from the effects of biotic and environmental factors that are expected to determine the probability of species persistence and have strong spatial autocorrelation (Dormann 2007). It is most likely, however, that sampling effort autocorrelation explains this result. The "home-range" of odonate researchers and its movements by roads or large rivers in the amazon appear to be the primary source of these autocorrelation patterns.

The existence of a correlation between species and genera richness is intuitively reasonable and present the higher predictive power as a surrogate in this study. Considering the existence of large areas without any odonate records, the reduction of the taxonomic resolution to the genera level in faunal inventories is an acceptable compromise to speed-up the process of conservation priority setting as it is also suggested in other studies (Balmford et al. 2000). Present information suggests that this choice is especially important to areas in Central Brazil and Amazon, where the lack of distributional information is a possible result of the lack of odonatologists.

Otherwise, compositional complementarities are preferred against species or genus richness for setting conservation priorities (Rodrigues \& Brooks 2007). This is mainly due to its ability to produce priority conservation areas with maximum diversity under the minimal area allocation (Pressey et al. 1997). Nevertheless, other recent articles demonstrate that species richness and especially genus richness have a high correlation to phylogenetic diversity, that is a desirable measure of biodiversity in a global change scenario (Forest et al. 2007). These results suggest that genus richness remain as an important tool for conservation planning and highlight the advantages in using genus richness as surrogate of odonate diversity.

The use of cross-taxa surrogates was intensely discussed but with very different outcomes. For instance, Ricketts et al (2002) showed that butterfly diversity is not a good surrogate for moth diversity the Rocky Mountains of the United 
States. Araujo et al. (2004) showed a strong correlation of species richness among plants, breeding birds, mammals and herptiles, with the exception of a poor correlation between birds with plants and herptiles. A recent revision consider cross-taxa surrogacy better than environmental diversity in an analysis of the literature (Rodrigues \& Brooks 2007). In general, our results suggest that cross-taxa surrogates are one of the better approaches in neotropical odonates.

Nevertheless, one problem in use Libellulidae as surrogate to total Odonata is that in $14,4 \%$ of the cells there is no Libellulidae registered so far. Under the restrictions to use the rarefaction technique this value increase to $48,3 \%$ of possible analyzed cells. Otherwise, the presence of other odonate groups in areas without Libellulidae suggests that they are not universally more easily captured and/or present in field collections than we anticipated. Nevertheless, this group presents a good predictive power and remains as an interesting surrogate, but it is expected to be less effective than the use of a higher-taxa approach. However, the dominance of Libellulidae in our database could be the result a several different bias of the collectors. In general, the Libellulidae are more abundant in anthropogenic habitats as dams and altered streams, which favored its capture by museum collectors and are the primary target of behavioral studies. Public awareness about biological diversity are usually aimed on species or groups that have some special appealing or are more known. In fact, the bias in visualization and collection of Libellulidae could suggest this group as a flagship due to the possibility to generate a public awareness.

Another interesting approach for surrogacy of species niche is to explore its relation to environmental variables. There is no doubt that some climate variables, especially temperature affect species distribution in general. Odonate species richness patterns in Britain ( Eversham \& Cooper 1998) were strongly affected by temperature but there is a clear variability of correlation coefficients among different latitude strips. Nevertheless, Keil et al. (2008), in a recent study in Europe, reject temperature as a primary determinant of species richness and also show a low predictive importance of precipitation. However, they were able to demonstrate an effect of environmental variables related to the water-energy hypothesis of species richness control (potential and actual evapotranspiration). At this moment, the low amount of distributional information precludes a formal evaluation of this hypothesis, which remains as an open avenue for future analysis.

Obviously, distributional data are not the only information that hinders conservation action in odonates. An indicator of how difficult is to obtain biological information, especially in the tropics, is that only a small fraction of the described species there is more information other than basic habitat preference and diagnostic anatomy. For a large proportion of the odonate species in Brazil, basic biological and ecological information including adult and larval habitat selection, which are key factors for proper conservation actions, is non-existent. These data are important to evaluate the biological mechanisms that determine the concordant distributional patterns among odonate families, such as habitat preferences or thermoregulatory constrains to devise a more deductive approach to evaluate cross-taxa surrogates.

The existence of large areas without any biogeographic information on odonates raises the question of how to accelerate the rate of getting this information. One suggested action that could be used in groups like birds, butterfly and odonates (that could get the public attention), is the training of "parataxonomists" to get such information. This term was created by Daniel Janzen, as a parallel to paramedic (Janzen 2004) to designate trained people that could do some important biodiversity collection, sorting and even performing low resolution taxonomic determination, without the training of an odonate taxonomist or ecologist. This approach could be implemented in a large country in Brazil with the special participation of under-graduate students, high-school students and local people, especially in the interior where they lack good opportunities for special education.

\section{Acknowledments}

P. H. C. Peixoto, K Furieri and M. V. C. Vital helped in the process of database compilation and organization. We are greatly indebted to C. E. Grelle and M. V. C. Vital for suggestions on an early version of this manuscript. P. De Marco is supported by a CNPq PQ fellowship and several other research grants.

\section{References}

Araujo MB, Densham PJ \& Williams PH, 2004. Representing species in reserves from patterns of assemblage diversity. Journal of Biogeography, 31:1037-1050. http://dx.doi. org/10.1111/j.1365-2699.2004.01051.x

Balmford A, Lyon AJE \& Lang RM, 2000. Testing the highertaxon approach to conservation planning in a megadiverse group: the macrofungi. Biological Conservation, 93:209-217. http://dx.doi.org/10.1016/S0006-3207(99)00140-8

Bini LM et al., 2009. Coefficient shifts in geographical ecology: an empirical evaluation of spatial and non-spatial regression. Ecography, 32:193-204. http://dx.doi. org/10.1111/j.1600-0587.2009.05717.x

Bruner AG, Gullison RE \& Balmford A, 2004. Financial costs and shortfalls of managing and expanding protected-area systems in developing countries. BioScience, 54:1119-1126. http://dx.doi.org/10.1641/0006-3568(2004)054[1119:FCAS $\mathrm{OM}] 2.0 . \mathrm{CO} ; 2$

De Marco Junior P \& Vianna DM, 2005. Distribuição do esforço de coleta de Odonata no Brasil: subsídios para escolha de áreas prioritárias para levantamentos faunísticos. Lundiana, 6:13-26.

Diniz JAF, De Marco P \& Hawkins BA, 2010. Defying the curse of ignorance: perspectives in insect macroecology 
and conservation biogeography. Insect Conservation and Diversity, 3:172-179.

Dormann CF, 2007. Effects of incorporating spatial autocorrelation into the analysis of species distribution data. Global Ecology and Biogeography, 16:129-138. http:// dx.doi.org/10.1111/j.1466-8238.2006.00279.x

Dutilleul P, 1993. Modifying the t-test for assessing the correlation between two spatial processes. Biometrics, 49:305314. http://dx.doi.org/10.2307/2532625

Eversham BC \& Cooper JM, 1998. Dragonfly species-richness and temperature: national patterns and latitude trends in Britain. Odonatologica, 27:307-316.

Faith DP, 2003. Environmental diversity (ED) as surrogate information for species-level biodiversity. Ecography, 26:374379. http://dx.doi.org/10.1034/j.1600-0587.2003.03300.x

Forest F et al., 2007. Preserving the evolutionary potential of floras in biodiversity hotspots. Nature, 445:757-760. PMid:17301791. http://dx.doi.org/10.1038/nature05587

Galindo-Leal C \& Câmara IG, 2003. The Atlantic forest of South America: Biodiversity status, threats, and outlook. Whashington: Island Press.

Grelle CEV, 2002. Is higher-taxon analysis an useful surrogate of species richness in studies of Neotropical mammal diversity? Biological Conservation, 108:101-106. http:// dx.doi.org/10.1016/S0006-3207(02)00094-0

Janzen DH, 2004. Setting up tropical biodiversity for conservation through non-damaging use: participation by parataxonomists. Journal of Applied Ecology, 41:181-187. http://dx.doi.org/10.1111/j.1365-2664.2004.00879.x

Keil P, Simova I \& Hawkins BA, 2008. Water-energy and the geographical species richness pattern of European and North African dragonflies (Odonata). Insect Conservation and Diversity, 1:142-150. http://dx.doi. org/10.1111/j.1752-4598.2008.00019.x

Laurance WF, 1999. Reflections on the tropical deforestation crisis. Biological Conservation, 91:109-117. http://dx.doi. org/10.1016/S0006-3207(99)00088-9

Legendre L \& Legendre P, 1998. Numerical Ecology. Amsterdam: Elsevier.
McGeoch MA, 1998. The selection, testing and application of terrestrial insects as bioindicators. Biological Reviews, 73:181201. http://dx.doi.org/10.1017/S000632319700515X

Oertli B, 2008. The use of dragonflies in the assessment and monitoring of aquatic habitats. In: Cordoba-Aguilar A (ed.). Model organisms for ecological and evolutionary research. Oxford: Oxford University Press.

Pawar SS et al., 2007. Conservation biogeography in North-east India: hierarchical analysis of cross-taxon distributional congruence. Diversity and Distributions, 13:53-65.

Prendergast JR et al., 1993. Rare species, the coincidence of diversity hotspots and conservation strategies. Nature, 365:335-337. http://dx.doi.org/10.1038/365335a0

Pressey RL, Possingham HP \& Day JR, 1997. Effectiveness of alternative heuristic algorithms for identifying indicative minimum requirements for conservation reserves. Biological Conservation, 80:207-219. http://dx.doi.org/10.1016/ S0006-3207(96)00045-6

Rangel TF, Diniz JAF \& Bini LM, 2010. SAM: a comprehensive application for Spatial Analysis in Macroecology. Ecography, 33:46-50. http://dx.doi. org/10.1111/j.1600-0587.2009.06299.x

Ricketts TH, Daily GC \& Ehrlich PR, 2002. Does butterfly diversity predict moth diversity? Testing a popular indicator taxon at local scales. Biological Conservation, 103:361-370. http://dx.doi.org/10.1016/S0006-3207(01)00147-1

Rodrigues ASL \& Brooks TM, 2007. Shortcuts for biodiversity conservation planning: The effectiveness of surrogates. Annual Review of Ecology Evolution and Systematics, 38:713-737. http://dx.doi.org/10.1146/annurev.ecolsys.38.091206.095737

Sanders HL, 1968. Marine benthic diversity: A comparative study. The American Naturalist, 102:243-282. http://dx.doi. org/10.1086/282541

Silva DP, De Marco P \& Resende DC, 2010. Adult odonate abundance and community assemblage measures as indicators of stream ecological integrity: A case study. Ecological Indicators, 10:744-752. http://dx.doi.org/10.1016/j. ecolind.2009.12.004

Silva JMC, Rylands AB \& Fonseca GAB, 2005. The fate of the Amazonian areas of endemism. Conservation Biology, 19:689694. http://dx.doi.org/10.1111/j.1523-1739.2005.00705.x 